\title{
Matching Grants for New and Underutilized Vaccines in Resource-poor Settings: Determinants of Generation of New Money
}

Peter Mala*

Faculty of Medicine and Biology, Institute of Social and Preventive Medicine, University of Lausanne, Switzerland

${ }^{*}$ Corresponding author: Peter Mala, Faculty of Medicine and Biology, Institute of Social and Preventive Medicine, University of Lausanne, 10 Route de la Corniche, 1010 Lausanne, Switzerland, E-mail: peter.mala@unil.ch

Received date: January 31, 2018; Accepted date: February 10, 2018; Published date: February 17, 2018

Copyright: (C2018 Mala P. This is an open-access article distributed under the terms of the Creative Commons Attribution License, which permits unrestricted use, distribution, and reproduction in any medium, provided the original author and source are credited.

\begin{abstract}
Introduction: Since the expanded program on immunization (EPI) was introduced in low-income countries in 1974 , delivery of vaccines to children in need in these countries has largely depended on donor funding. Gavi introduced co-financing in attempts to address the problem of donor dependency in immunization programs in lowincome countries. This study examines the perception barriers that hinder the generation of a desired increase in domestic revenue allocation for immunization programs of recipient low-income countries.
\end{abstract}

Methods: Document review was conducted for the period 2010 to 2014 in the 4 countries implementing Gavi cofinancing arrangements for at least 4 years. Key informant interviews of 12 participants with a role in immunization planning and budgeting process were conducted in the same 4 countries. Descriptive analysis of quantitative and qualitative data was performed to determine co-finance patterns and contributing factors.

Results: Findings showed largely sustained levels of co-financing by countries without any significant increase in co-financing levels. Findings from qualitative analysis identified 2 concerns that represented perceived barriers of generation of new money among recipients participating in the co-financing arrangement; these were: understanding of the proposed co-financing solution and the capacity to contribute.

Conclusion: Findings show that desired increasing levels of co-financing by countries receiving matching grants has not been respected. This does not bode well for realization graduation from donor grants, and donor dependency may continue. The main contributing factors according to the findings are lack of consensus and shared common understanding among stakeholders of how co-financing arrangement is expected to work and what is expected of stakeholders, and lack of fiscal space to accommodate more immunization costs in the midst of other legitimate competing needs and budgetary constraints.

Keywords: Gavi; Immunization; Matching grants; Vaccines; Lowincome countries

\section{Introduction}

Since the expanded program on immunization (EPI) was introduced in low-income countries in 1974, delivery of vaccines to children in need in these countries has largely depended on donor funding [1]. In recent times, levels of donor funding for health have increased considerably [2], most notably in immunization programs of low-income countries, but effectiveness of the aid in terms of progression of recipients towards sustainable self-financing among beneficiary countries has not been achieved $[3,4]$. While many donors would like to see governments take over financial responsibility of immunization programs [5], ongoing introduction of expensive new vaccines has only increased concerns about sustained donor dependency among low-income countries [6,7].

Empathy and the need to help those in extreme need has been the main driver of donor aid to resource-poor settings [8]; however, this is being challenged by difficulties of weaning poor countries off aid, donor fatigue and emerging approaches to aid delivery such as matching grants. Grants are designed to induce response among recipient countries [9] and encourage expenditure on particular goods and services $[10,11]$. They constitute one of the primary instruments donors have for influencing delivery of priority health services among recipient countries. Most grants, including those that appear unconditional, are accompanied by explicit or implicit contracts that make it possible to influence a recipient's response according to the wishes of the donor [9].

Initially Gavi, a non-profit organization dedicated to increasing access to immunization in low-income countries, provided general or non-matching grants to national immunization programs [12], but due to lack of progress in sustainable self-financing among the recipient countries [3,13], a co-financing form of matching grant was introduced in 2008 with the aim of stimulating an increase in budgetary allocations from local revenue, and funding from other donors [14]. Under co-financing arrangements, grant recipients contribute to the total cost of new and underutilized vaccines from domestic revenue based on a mutually agreed upon formula [14].

A matching grant, also referred to as a conditional grant, targets a specific purpose, and may require the recipient to pay part of the cost of the intervention on the basis of a specified formula $[10,11,15]$; its 3 main formulations include competitive, co-financing and reverse matching grant [16]. According to theory, a matching grant has greater stimulatory effect on recipients' spending $[9,17,18]$, generation of 
alternative funding [19] and on expansion of provision of prioritized public goods [20]. However, other researchers have questioned the validity of grant response propositions of conventional theory because of the assumption of grant recipients as individual decision makers [21]. In practice, recipients tend to be groups of individuals whose response to grants is influenced by determinants of collective decision making such as administrative requirements, participant institutions in decision making $[17,18,21]$, alignment with recipients' preferences, and political interests $[4,20,22,23]$. Other grant response determinants include grant structure [18], economic conditions [18,24], and realistic budgets and knowledge of the true cost of target intervention [19].

Although much is known about determinants of grant response, to our knowledge, since the matching grant approach was introduced in national immunization programs of low-income countries, subjective perceptions of key informants that are important in shaping grant response have not been examined. The objective of this study is to contribute to a better understanding of why new funds have so far not been forthcoming under the co-financing arrangement in low-income countries receiving Gavi matching grants for national immunization programmes.

Even though difficulties in operationalizing the concept of new money has been reported [16] under the Gavi co-financing arrangement, new money is considered to be any increase in funding for immunization obtained by the grant recipients from local revenue budgetary allocations or funds from other donors. Using a qualitative case study approach, we examined patterns of co-financing by countries and perceptions of key stakeholders of the national immunization programs regarding the generation of new money.

\section{Methods}

\section{Study design}

This study used mixed methods; document review and key informant interviews were conducted to address the question of cofinancing patterns and to identify determinants of co-financing patterns among low-income countries receiving Gavi matching grants for their national immunization programme budgets. Regarding the document review component of the study, complete copies of annual progress reports were retrieved from Gavi's website for data extraction and analysis. Retrieval was restricted to the period from 2008-2014. The year 2008 was the chosen because this was the year that Gavi introduced the co-financing policy. Relevant data extracted included details of funding received from Gavi and other donors, and governments' contributions to the national immunization program budget. However, relevant immunization financing data was only available in annual progress reports published from 2010 onwards.
This study also used qualitative approach for 2 main reasons. Firstly, the study explores respondents' views and their understanding of factors that enable or hinder countries from generating new money for increasing levels of co-financing as expected from the matching grant design. Secondly, while quantitative research methods are good at demonstrating trends and patterns of co-financing, qualitative methods are better suited to identifying determinants that influence co-financing levels [25].

\section{Participants}

The study countries were selected purposefully from among the 77 countries that have adopted the cMYP guidelines to develop national immunization programme budgets and financing plans. Purposive selection of the study countries was intentional because given that cMYP implementation occurs in 2-4-year immunization planning cycles in countries, it was important to identify countries that have recent memory and recollection of the cMYP planning process in order to be able to obtain relevant information respondents. For this reason, a deliberate choice was made to select countries where potential respondents have recently or were in the process of preparing their multiyear immunization financing plans based on the cMYP guidelines. Additional considerations for selection included whether the key immunization program professionals and stakeholders involved could be accessed for interviews, and their willingness to participate in the study. The 4 countries that met inclusion criteria were Kenya, Ghana, Pakistan, and Sudan.

Professionals who have been actively involved in implementation of the guidelines from the lead vaccine unit, collaborating technical units, and technical partner agency were identified with the assistance of the WHO unit responsible for technical support for immunization and implementation of cMYP guidelines. A formal introductory message was sent to the participants as well as a brief description of the study seeking their consent to participate in the study.

Out of 14 potential respondents who were contacted, 12 respondents accepted to participate in the interview. Among the 2 who did not participate, 1 participant was not interviewed due several failed attempts to schedule the interview after initial introduction, and 1 did not want to participate due to personal reasons. The respondents included immunization programme managers from the ministries of health, technical lead for immunization at the WHO country office of the countries concerned or their nominees with good knowledge of the programme, and subject area experts from technical units who have been involved in the implementation of cMYP guidelines for immunization planning Table 1 .

\begin{tabular}{|l|l|l|l|l|}
\hline Country & Sex & Affiliation & Expertise & Experience \\
\hline Ghana & & & & \\
\hline RGK_G01 & Male & Government & Immunization & $10-15 \mathrm{yr}$ \\
\hline RGS_P02 & Male & Partner agency & Health economics & $>15 \mathrm{yr}$ \\
\hline RGS_P03 & Male & Partner agency & Immunization & $10-15 \mathrm{yr}$ \\
\hline Kenya & & & & \\
\hline
\end{tabular}


Citation: Mala P (2018) Matching Grants for New and Underutilized Vaccines in Resource-poor Settings: Determinants of Generation of New Money. J Vaccines Vaccin 9: 387. doi:10.4172/2157-7560.1000387

Page 3 of 7

\begin{tabular}{|l|l|l|l|l|}
\hline RKH_P04 & Male & Partner agency & Health systems & $>15 \mathrm{yr}$ \\
\hline RKK_P05 & Male & Partner agency & Immunization & $10-15 \mathrm{yr}$ \\
\hline RKO_G06 & Male & Government & Health planning \& policy & $>15 \mathrm{yr}$ \\
\hline RKT_G07 & Female & Government & Health economics & $<10 \mathrm{yr}$ \\
\hline Pakistan & & & & $>15 \mathrm{yr}$ \\
\hline RPR_P08 & Male & Partner agency & Immunization & $<10 \mathrm{yr}$ \\
\hline RPW_P09 & Male & Partner agency & Immunization & \\
\hline Sudan & & & & $10-15 \mathrm{yr}$ \\
\hline RSH_P10 & Female & Partner agency & Health systems & $>15 \mathrm{yr}$ \\
\hline RSI_G11 & Male & Government & Health planning \& policy & $10-15 \mathrm{yr}$ \\
\hline RSI_G12 & Female & Government & Epidemiology & \\
\hline
\end{tabular}

Table 1: Characteristic of the 12 respondents from four study countries.

\section{Conduct of the interviews}

A semi-structured interview schedule was developed to guide the interviews and to ensure comparability of the 12 interviews. The questions were pilot tested with one of the respondents after which further refinements were made to improve the questions. The interviews were conducted through a combination of face-to-face and phone interviews depending on accessibility of the respondents. Each interview started with an introduction and explanation of the purpose. Each of the interviews lasted 35-45 min. Participants were informed of measures taken to ensure confidentiality and anonymity, and that they were free to choose not to answer any question they felt uncomfortable with. Each interview was audiotaped with the consent of the respondents.

\section{Data analysis}

Descriptive analysis of quantitative data extracted from annual progress reports was performed using Microsoft Excel (Microsoft, Redmond, WA) to determine patterns of immunization financing and funding sources. The interviews were recorded on a digital recorder (i.e. Olympus DM-901, Olympus, Shinjuku, Tokyo, Japan) with consent of the respondents. Each of the recordings was transcribed to text with assistance of Dragon NaturallySpeaking voice recognition software (Dragon Systems of Newton, MA). The text constituted the data that was uploaded to statistical analysis software for qualitative data, NVivo 11.0 (QRS International, Melbourne, Australia). The application was used to scrutinize the transcripts and identify all text elements on factors affecting immunization budget co-financing levels by the countries. Each text element was coded according types of factor. Codes were derived from data, not decided a priori.

During the first round of analysis 3 codes or factors were identified for the grouping of the text elements. These were understanding of grant design, donor dependency, and fiscal capacity to contribute. Subsequent rounds of analysis recognized similarities between text elements coded under donor dependency and those that were coded under fiscal capacity and both were collapsed under fiscal capacity.

\section{Results}

Quantitative findings on co-financing patterns and general trends as well results of qualitative analysis of determinants co-financing levels are presented by country in this section.

\section{a) Ghana}

Between 2010 and 2013, the immunization budget for new and underutilized vaccines in Ghana increased from \$8.3 million to \$21.7 million (Table 2). During the same period, Gavi grants increased from $\$ 7.8$ million to 19.8 million. Gavi grants accounted for over $90 \%$ of the national immunization budget for new and underutilized vaccines. Over the same period, government co-financing levels increased from $\$ 0.6$ million in 2010 to $\$ 1.8$ million in 2013. In terms of proportion, there was a sharp drop in Gavi grants in 2011 and this raising of the proportion of government co-financing to $27 \%$ from $6 \%$ in 2010 was followed by a drop to $7 \%$ in 2012 as Gavi grants increased.

Findings from quantitative data show that even though Ghana generally kept up with the minimum level of matching funds it contributed every year, there was not an increase in matching grants from government revenue and alternative donors as expected. The level of government contribution remained the same as one respondent affirmed [RGS_P02]. Findings show that understanding of how the grant design was supposed to work, and fiscal capacity of the country to contribute more were the main contributing factors to failure to generate new money for increasing co-financing levels Table 2.

\begin{tabular}{|l|l|l|l|l|l|l|}
\hline Country & Funding source & $\mathbf{2 0 1 0}$ & $\mathbf{2 0 1 1}$ & $\mathbf{2 0 1 2}$ & $\mathbf{2 0 1 3}$ & $\mathbf{2 0 1 4}$ \\
\hline Ghana (GNI \$1620) & $\begin{array}{l}\text { Gavi matching grants } \\
(\$)\end{array}$ & 7785975 & 2473500 & 35459489 & 19829560 & - \\
\hline
\end{tabular}


Citation: Mala P (2018) Matching Grants for New and Underutilized Vaccines in Resource-poor Settings: Determinants of Generation of New Money. J Vaccines Vaccin 9: 387. doi:10.4172/2157-7560.1000387

Page 4 of 7

\begin{tabular}{|c|c|c|c|c|c|c|}
\hline & $\begin{array}{l}\text { Government } \\
\text { financing (\$) }\end{array}$ & 567290 & 897603 & 2150914 & 1846329 & - \\
\hline & $\begin{array}{l}\text { Co-financing } \\
\text { proportion (\%) }\end{array}$ & $7 \%$ & $27 \%$ & $6 \%$ & $9 \%$ & \\
\hline & Total (\$) & 8353265 & 3371103 & 37610403 & 21675889 & - \\
\hline \multirow{4}{*}{ Kenya (GNI \$1280) } & $\begin{array}{l}\text { Gavi matching grants } \\
\text { (\$) }\end{array}$ & 21698989 & 61761489 & 52557000 & 33516000 & 30305500 \\
\hline & $\begin{array}{l}\text { Government } \\
\text { financing }(\$)\end{array}$ & 1582637 & 2911176 & 3477215 & 2671172 & 2244500 \\
\hline & $\begin{array}{l}\text { Co-financing } \\
\text { proportion (\%) }\end{array}$ & $7 \%$ & $5 \%$ & $6 \%$ & $7 \%$ & $7 \%$ \\
\hline & Total (\$) & 23281626 & 64672665 & 56034215 & 36187172 & 32550000 \\
\hline \multirow{4}{*}{$\begin{array}{l}\begin{array}{l}\text { Pakistan } \\
\text { \$1410) }\end{array} \quad \text { (GNI } \\
\end{array}$} & $\begin{array}{l}\text { Gavi matching grants } \\
\text { (\$) }\end{array}$ & 43801222 & 35383000 & 93409000 & 7405189 & - \\
\hline & $\begin{array}{l}\text { Government } \\
\text { financing }(\$)\end{array}$ & 5559176 & 5559176 & 10902943 & 1365765 & 8515373 \\
\hline & $\begin{array}{l}\text { Co-financing } \\
\text { proportion (\%) }\end{array}$ & $11 \%$ & $14 \%$ & $10 \%$ & $16 \%$ & - \\
\hline & Total (\$) & 49360398 & 40942176 & 104311943 & 8770954 & 8567140 \\
\hline \multirow{4}{*}{ Sudan (GNI \$1740) } & $\begin{array}{l}\text { Gavi matching grants } \\
\text { (\$) }\end{array}$ & - & 26135789 & 29914980 & 30685986 & 33735746 \\
\hline & $\begin{array}{l}\text { Government } \\
\text { financing }(\$)\end{array}$ & - & 876715 & 1078483 & 2170155 & 2818768 \\
\hline & $\begin{array}{l}\text { Co-financing } \\
\text { proportion (\%) }\end{array}$ & - & $3 \%$ & $3 \%$ & $7 \%$ & $8 \%$ \\
\hline & Total (\$) & - & 27012504 & 30993463 & 32856141 & 36554514 \\
\hline
\end{tabular}

Table 2: Gavi grants and government co-financing of new and under-utilized vaccines in Ghana from 2010 to 2014 in US dollars

Regarding grant design, contributions from the government, according to one respondent, has remained at the same level in Ghana based on a co-financing formula because of understanding of how cofinancing arrangement is supposed to work: "Government has maintained co-financing level at about $4 \%$, GAVI pays about $96 \%$ of the budget for new and underutilized vaccines" [RGK_G01]. Similar observations were made among some potential donors who felt that they could not contribute more because they were already contributing through Gavi, the main donor, as illustrated by one of the respondents: "Some partners have given money but most partners feel they are already contributing through Gavi” [RGS_P02].

Fiscal capacity appeared to limit Ghana's capacity to increase the level of matching funds. According to the findings, Ghana for example, has experienced funding deficits that affected allocations to programmes including immunization [RGS_P02], and at one point even defaulted on the minimum required contribution of matching funds based on agreed upon co-financing formula as one respondent observed: "The government agreed to co-finance and signed a memorandum of understanding with Gavi but we defaulted and that had a very unfortunate consequence on us" [RGS_G01].

\section{b) Kenya}

Between 2010 and 2014, immunization budget for new and underutilized vaccines in Kenya increased from \$23.3 million to $\$ 32.6$ million (Table 2). During the same period Gavi grants increased from $\$ 21.7$ million to 30.3 million. Gavi grants account for over $90 \%$ of the national immunization budget for new and underutilized vaccines. Over the same period government co-financing level remained low; it increased from \$1.6 million in 2010 to $\$ 2.2$ million in 2014. This represented an average annual government co-financing level of $6 \%$ over the 5 -year period. There was only a $2 \%$ increase in government co-financing levels from $5 \%-7 \%$ over the same period.

Even though Kenya has also kept up with co-financing obligations according to the prescribed formula, findings show that there has been no meaningful increase in co-financing levels by the government as further illustrated by one respondent: "So far I can't say that we're actually moving towards independence because what the government has been co-financing for some years now is still the same, it has not improved" [RKT_G07]. Two contributing factors identified by the analysis were how the grant design was understood by the government and potential alternative donors, and fiscal capacity of the country to contribute more from local revenue 
Regarding the understanding of the grant design by the government, it appears expectations to progressively contribute increasing amounts was not understood because findings show that even the minimum that was being contributed was being done so because it is conditional, as one respondent observed: "Whatever government contributes right now, it is because it is conditional but it should not be like that" [RKO_G06]. Furthermore, as observed by one respondent, there is little motivation for the government to contribute more as long as donor grant is still available: "The reality is that if you fund a certain activity, the government will not budget for it; so as long as that funding still exists, I don't think any government will attempt to replace it" [RKK_P05].

Misunderstanding of expectation of co-financing arrangements was also observed among the potential alternative donors. As illustrated by one of the respondents these partners felt that they were already contributing through Gavi the main grantor: "Some of the donors make the argument that they are providing money through Gavi and in their view they feel that they are already contributing" [RKH_P04]. And for this reason, they did not contribute more towards the immunization budget for new and underutilized vaccines.

Fiscal capacity constraint amidst competing needs featured prominently as one of the main limitations on the country's capacity to generate new money from local revenue towards the immunization budget for new and underutilized vaccines. As illustrated by one of the respondents, the country appeared to face difficulties of trying to balance other health priorities and allocating more resources for immunization programme: "I think the issue of why governments are taking up or not taking up more costs is unfair judgment of the governments; they are facing many competing health problems, they are struggling with HIV, they are struggling with Malaria which is killing people as they are seeing as opposed to immunization which is more of a preventive strategy. It is not that the immunization program is operating in a vacuum where there is money and it is just about convincing people to use the money for immunization." [RKH_P04].

\section{c) Pakistan}

Between 2010 and 2012, the immunization budget for new and underutilized vaccines in Pakistan increased from \$49.4 million to $\$ 107.3$ million (Table 2). During the same period Gavi grants increased from $\$ 43.8$ million to 93.4 million. Over the same period government co-financing levels increased from $\$ 5.6$ million in 2010 to $\$ 10.9$ million in 2012. Gavi grants accounted for over $80 \%$ of the national the budget during this period. In 2014, the total national budget for new and underutilized vaccines decreased to $\$ 8.8$ million dollars and Gavi contributed $\$ 7.4$ million. The average annual government co-financing level was $12 \%$ between 2010 and 2013 with $5 \%$ increase from $11 \%$ in 2010 to $16 \%$ in 2013.

Even though Pakistan has registered an increase in co-financing on average there has been no deliberate effort to increase co-financing levels by the government. Findings are similar to what has been observed in the other countries-understanding of the grant design and fiscal capacity of the government to pay more are the main contributing factors. According to one respondent who addressed this issue, government did not increase levels of contribution of matching funds because the country had not arrived at the stage of exiting the co-financing arrangement: "Government funding is not increasing because the country is not in the path to graduation yet. But ultimately the full cost will be taken over by the government once we are on the path to graduation" [RPR_P08]. Regarding fiscal capacity to pay more, local budgetary constraints also appeared to play a role in failure to realize increasing levels of the government's matching funds, beyond the required minimum, as illustrated by the following observation: "Without Gavi support it will be very difficult for any government to finance the immunization budget" [RPR_P08].

\section{d) Sudan}

Between 2011 and 2014, immunization budget for new and underutilized vaccines in Sudan increased from \$27 million to \$36.6 million (Table 2). During the same period Gavi grants increased from \$26 million to 33.7 million. Gavi support represented the main source of funding for the national immunization budget for new and underutilized vaccines accounting for over $90 \%$ of the budget. Over the same period government co-financing levels remained modest, increasing from \$0.9 million in 2011 to $\$ 2.8$ million in 2014. In terms of proportion this represented an average annual government cofinancing level of $5 \%$ over the 5-year period; the general trend showed only marginal increase in government co-financing levels over the period from $3 \%-8 \%$.

Sudan had a marginal increase in co-financing levels as quantitative analysis has shown. Qualitative findings showed that co-financing could have been a factor according to one respondent [RSI_G11]; however, this increase appeared to be generalized across sectors and was probably due to growth in budgetary allocations that tend to occur over time in all government programmes as one respondent observed: "There is some increase in government financing of immunization since cMYP was introduced but this also applies to other sectors, so the increase in probably normal annual growth in budget" [RSH_P10]. Additionally, while it was acknowledged that contributions from alternative partners to immunization budget has not changed, it was not clear why there has been no increase according to the respondent: "I do not think funding from alternative donors has changed much, it is still the same" [RSH_P10]

\section{Discussion}

The aim of this study was to identify determinants of generation of new money for national immunization budgets under co-financing arrangements by low-income countries. Quantitative findings showed that co-funding levels as a proportion of the immunization budget for new and underutilized vaccines did not increased significantly in all 4 countries between 2010 and 2014. Findings show that over the study period, Gavi was the main source of financing for new and underutilized vaccines with grants from Gavi accounting for over $85 \%$ of the budgets of the 4 countries for new and underutilized vaccines. The average co-financing level among the countries was less than $15 \%$ of the total annual immunization budget in all the 4 countries (range: 5\%-13\%). These findings were triangulated with results from interviews of key informants in order to better understand the cofinancing patterns in the study countries and contributing factors to the observed patterns.

An analysis of interview information showed a lack of significant increase in co-financing levels by the countries as most respondents observed that there had been no significant increase in co-financing levels in their respective countries. The findings identified 2 main determinants of generation of new money for co-financing contributions from national revenue. These factors were: understanding of the co-financing arrangement, and fiscal capacity of the low-income to be able to contribute more. Regarding failure to 
generate new money from potential alternative donors, only understanding of the co-financing arrangement was found to be a determinant.

Grant recipients' understanding of how a chosen solution works and what is expected from them is important for the realization of the desired response among recipients. These findings showed lack of common understanding of expectations of the co-financing arrangement even though memorandums of understanding were signed between the donor and the recipients. Countries seemed to believe that there was no need to contribute beyond the bare minimum prescribed by the co-financing formula, and others confused cost sharing with co-financing by arguing that they are already contributing to immunization costs in other ways [19]. Lack of common understanding is likely to have had a significant impact on levels of cofinancing funds from the government. Studies have shown that in instances where there is lack of common understanding between donors and grant recipients, recipient government are unlikely to increase their share of contributions but rather tend to remove their own money from the activity $[4,26,27]$.

The lack of capacity to contribute more appeared to be a significant factor in the countries' failure to contribute more than the minimum prescribed despite expectations of the co-financing arrangement. Cofunding levels were set based on fiscal space analysis among the recipient low-income countries [14] and as the economies of these countries have continued to grow, there was the expectation that they should be able to contribute more to their immunization costs [28]. However, findings show that the recipients were only able to meet their basic co-funding obligations, and could not rise to the challenge of progressively taking over the full cost of immunization. The question of competing needs in an environment of limited resources also kept appearing in the interviews as major limitation to increasing levels of co-financing. According to Waddington, governments of low-income countries will not commit more resources to an activity because it is important because many other programmes fit this description and they cannot afford them all [29].

The main limitation of this study was the small number of countries that participated in the study. There was a need to strike a balance between a small study sample for the level of detail and large volume of information expected from an in-depth interview approach. Additionally, the study did not include countries that have been able to exit the grant and take on the full cost of the new and underutilized vaccines. The generalizability of our findings therefore could be questioned.

Despite the limitations, these findings have shed important light into the discrepancy between the expected stimulative effect of the matching grant arrangement on country co-financing levels and the observed lack of the same. The findings have also contributed to our understanding of determinants of grant response among donor grant recipients in the context of immunization financing in low-income countries. According to the findings, realization of desired stimulatory effect of co-financing on grant recipient countries for immunization budgets and graduation from donor grants may not be realized unless there is consensus and shared common understanding among stakeholders of how co-financing arrangement is expected to work and what is expected of stakeholders. Furthermore, as long as low-income countries continue to experience poor economic growth, legitimate competing needs and budgetary constraints, they are unlikely to spend more on immunization and donor dependency in immunization financing is likely to continue.

\section{References}

1. Reid M, Fleck F (2014) The immunization programme that saved millions of lives. Bull World Health Organ 92: 314-315.

2. Ravishankar N, Gubbins P, Cooley RJ (2009) Financing of global health: tracking development assistance for health from 1990 to 2007. The Lancet 373: 2113-2124.

3. Lydon P, Levine R, Makinen M (2008) Introducing new vaccines in the poorest countries: what did we learn from the GAVI experience with financial sustainability? Vaccine 26: 6706-6716.

4. Farag M, Nandakumar AK, Wallack SS, Gaumer G, Hodgkin D (2009) Does funding from donors displace government spending for health in developing countries? Health Aff 28: 1045-1055.

5. Batson A (1998) Sustainable introduction of affordable new vaccines: the targeting strategy. Vaccine 16: 93-98.

6. Kamara L, Lydon P, Bilous J (2013) Global Immunization Vision and Strategy (GIVS): a mid-term analysis of progress in 50 countries. Health policy plan 28: 11-19.

7. Wolfson LJ, Gasse F, Lee-Martin SP (2008) Estimating the costs of achieving the WHO-UNICEF Global Immunization Vision and Strategy, 2006-2015. Bull World Health Organ 86: 27-39.

8. Ooms G, Hammonds R, Waris A, Criel B, Van Damme W, et al. (2014) Beyond health aid: would an international equalization scheme for universal health coverage serve the international collective interest? Glob Health 10: 41.

9. Brennan G, Pincus J (1990) An implicit contract theory of intergovernmental grants. Publius 20: 129-144.

10. Thurow L (1966) The theory of grants-in-aid. Nat Tax J 19: 373-377.

11. http://www.svt.ntnu.no/iso/jorn.rattso/Papers/lebjrtempgrants.pdf

12. Lu C, Michaud CM, Gakidou E, Khan K, Murray CJ (2006) Effect of the Global Alliance for Vaccines and Immunisation on diphtheria, tetanus, and pertussis vaccine coverage: an independent assessment. Lancet 368: 1088-1095.

13. Zuber PLF, El-Ziq I, Kaddar M (2011) Sustaining GAVI-supported vaccine introductions in resource-poor countries. Vaccine 29: 3149-3154.

14. Saxenian H, Cornejo S, Thorien K, Hecht R, Schwalbe N (2011) An analysis of how the GAVI alliance and low- and middle-income countries can share costs of new vaccines. Health Aff 30: 1122-1133.

15. http://siteresources.worldbank.org/PSGLP/Resources/ IntergovernmentalFiscalTransfers.pdf

16. http://philvol.sanford.duke.edu/documents/schuster89-08.pdf

17. Romer T, Rosenthal H (1980) An institutional theory of the effect of intergovernmental grants. Nat Tax J 33: 451.

18. Gist JR (1988) Fiscal austerity, grant structures and local expenditure response. Policy Stud J 16: 687-712.

19. Downs CF (1979) Sources of funds to meet NHPRC matching grants. Am Arch 42: 466-468.

20. Bracco E, Lockwood B, Porcelli F, Redoano M (2015) Intergovernmental grants as signals and the alignment effect: Theory and evidence. J Pub Econ 123: 78-91.

21. Bradford DF, Oates WE (1971) Towards a predictive theory of intergovernmental grants. Am Econ Rev 61: 440-448.

22. Rittenoure LR, Pluta JE (1977) Theory of intergovernmental grants and local government. Growth Change 8: 31-37.

23. Grossman PJ (1989) Intergovernmental grants and grantor government own-purpose expenditures. Nat Tax J 42: 487-494.

24. Singh N, Thomas R (1989) Matching grants versus block grants with imperfect information. Nat Tax J 42: 191-203.

25. Slade SC, Kent P, Bucknall T, Molloy E, Patel S, et al. (2015) Barriers to primary care clinician adherence to clinical guidelines for the management of low back pain: protocol of a systematic review and metasynthesis of qualitative studies. Bmj Open 5: e007265.

26. Adam T, Amorim BG, Edwards SJ (2005 ) Capacity constraints to the adoption of new interventions: consultation time and the Integrated 
Citation: Mala P (2018) Matching Grants for New and Underutilized Vaccines in Resource-poor Settings: Determinants of Generation of New Money. J Vaccines Vaccin 9: 387. doi:10.4172/2157-7560.1000387

Page 7 of 7

Management of Childhood Illness in Brazil. Health Policy Plan 20: i49i57.

27. Booth D (2012) Aid effectiveness: bringing country ownership (and politics) back in. Conflict, Security \& Development 12: 537-558.

28. Nader AA, de Quadros C, Politi C, McQuestion M (2015) An analysis of government immunization program expenditures in lower and lower middle income countries 2006-12. Health Policy Plan 30: 281-288.
29. Waddington C (2004) Does earmarked donor funding make it more or less likely that developing countries will allocate their resources towards, programmes that yield the greatest Health benefits? Bull World Health Organ 82: 703-706. 